\title{
Selection of Parameters and Strategies to Reduce Energy Consumption and Improve Surface Quality in EN-AW 7075 Molds Machining
}

\author{
Oscar Rodriguez-Alabanda ${ }^{\mathbb{D}}$, Maria Trinidad Bonilla, Guillermo Guerrero-Vaca ${ }^{\mathbb{D}}$ and \\ Pablo Eduardo Romero * (D) \\ Department of Mechanical Engineering, University of Cordoba, Medina Azahara Avenue, 5, 14071 Cordoba, \\ Spain; orodriguez@uco.es (O.R.-A.); p32bolom@uco.es (M.T.B.); guillermo.guerrero@uco.es (G.G.-V.) \\ * Correspondence: p62rocap@uco.es; Tel.: +34-957-212-235
}

Received: 3 August 2018; Accepted: 28 August 2018; Published: 31 August 2018

\begin{abstract}
The machining of cavities for blow molding is a long and costly process, with the objective of obtaining an excellent surface finish with the minimal possible electrical energy consumption (EEC). This work has studied which combination of cutting parameters and cutting strategies to use to achieve an optimum surface finish on the mold using the minimal associated EEC: in roughing operation, tool path strategy and axial depth of cut were studied; in finishing operation, tool path strategy, spindle-speed, feed-rate, and step-over were evaluated. Thirty-two molds were machined in blocks of aluminium alloy EN-AW 7075 T6 in a machining center of a three-axis, following an orthogonal design of experiments. The analysis of results demonstrates that: a roughing strategy has influence on the surface roughness on the bottom of the mold; a finishing strategy is an influential factor on the surface roughness on the walls of the mold; certain parameters have no relevance on the surface roughness but have an influence on the EEC; an adequate selection of cutting strategies and cutting parameters permit an improvement of surface roughness of up to $70 \%$, and a reduction of $40 \%$ in EEC, compared to the less favorable tests.
\end{abstract}

Keywords: mold; machining; surface roughness; electrical energy consumption

\section{Introduction}

Metal molds are some of the tools most used in the industry today. They are used to shape thermoplastic materials through different techniques [1]: injection (parts for the car industry), thermoforming (packaging), rotational molding (kayaks), and compression molding and blow molding (food containers).

The molds are produced by milling, in a machining center with a three- or five-axis [2]. The machining of the molds is undertaken in two stages. The first stage, known as roughing, is for the elimination of the main mold cavity without being concerned with the surface roughness obtained. This operation is usually carried out with a robust flat-end tool. The second stage, known as finishing, permits a fine surface roughness, eliminating the remaining material. This is usually carried out with tools of a smaller diameter and hemispherical end.

The tool-path that the tool has to follow during both phases of milling is undertaken by a pocketing strategy. There are multiple types of strategies, although the most used and studied are the raster (zig-zag, ZZ) and 3-D offset (contour-parallel, CP) [3].

In the manufacturing of a mold, the most important parameter is the surface roughness obtained [4]. In the literature, there is an abundance of references on the study of technical parameters with greater influence on surface finishing [5-8]. Normally, geometrically simple molds are chosen, 
and the roughness is measured at the bottom of the pocket [9]. Nevertheless, little attention is paid to the roughness of the walls of the mold [10].

Some authors have studied the impact of the finishing strategies on the quality of the surface roughness obtained. For 2.5-D milling, Gologlu and Sakarya [11] studied, via the Taguchi method, three types of strategies (one-direction, ZZ, and $\mathrm{CP}$ ) and four cutter parameters (cutting velocity, feed rate, depth of cut, and stepover). Also, Romero et al. [12] compared the ZZ and CP strategy for three different pocket geometries (concave, and convex with and without islands). For complex geometries, Ramos, Relvas, and Simões [13] compared different strategies for finishing (ZZ, CP, and radial) using the same strategies for roughing in every case, while Fagili de Souza et al. [14] studied four different finishing strategies (3-D offset, spiral, radial path, and ZZ) for mold applications. Schützer, Helleno, and Castellari [15] compared a ZZ strategy $\left(45^{\circ}\right)$ in finishing with a mix formed by four strategies adapted to the different regions of the geometry. Normally, the studies found in the literature are focused on finishing strategies and do not analyze the influence of roughing strategies on the surface roughness obtained on the complex surface [13-16].

In recent years, a large number of authors have focused their work on reducing the electrical energy used in the manufacturing processes [17,18]. Yoon et al. [19] have compared which method (bulk forming, substractive process, or additive process) consumes less electrical energy to manufacture the same part. Priarone [20] has evaluated the electrical consumption of a shaping grinding process for different process parameters via a full factorial experimental plan. Eden and Mativenga [21] have quantified the electrical consumption of a milling machine for different linear paths (G1) and circular paths (G2 and G3) in order to predict the electric demand of the machine during the execution of a NC program. Guerra-Zubiaga et al. [22] have studied different cutting trajectories and cutting parameters (feed rate, spindle speed, and depth of cut) in a slot milling process to analyze its influence on electrical consumption of the machining center. Kant and Sangwan [23] have developed a predictive model for the minimization of EEC and surface roughness during the machining of AISI 1045 steel. Based on simulations, $\mathrm{Xu}$ and Tang [24] have proposed two energy-saving strategies for rough milling tool path planning. Pavanasar et al. [25] have proposed a toolpath strategy that consumes at least $20 \%$ less energy than any conventional toolpath.

The present study has the following main objective: to study different cutting strategies and cutting parameters during the machining of a mold to determine which combination allows one to reach a better surface roughness on the bottom and walls of the cavity with the least possible EEC. For this purpose, an orthogonal design of experiments (DOE) was developed, made up of 32 tests. The variables included in the DOE were: strategy on roughing, axial depth of cut on roughing, strategy on finishing, spindle-speed in finishing, feed-rate in finishing, and step-over in finishing. All the tests were undertaken on EN AW 7075 T6 prismatic parts, using a machining center of a three-axis and coolant.

The work layout is in the following manner: Section 2 describes the materials and the methodology used throughout the tests. Section 3 will show the results obtained; those results will then be discussed in Section 4. Finally, the conclusions will be presented in Section 5.

\section{Materials and Methods}

The molds designed for the experiments have a particular geometry in order to oblige the tool to work with different parts of its edge (Figure 1): the bottom shows a step and is assembled with planes of different gradients, and the walls have a certain slope (they are not vertical). The 3-D pocket is open on one side to facilitate the readings of the roughness meter.

The cavities were machined with a machining center of a three-axis, a Chevalier, QP2026-L model, whose spindle worked at a maximum of $8000 \mathrm{rpm}$. The machine was equipped with a numerical control unit, a Fanuc, 0i-MC model, which worked with the look-ahead function activated. All the tests were carried out with refrigerant, based on an oil emulsion Besal 5 (Brugarolas, Rubí, Barcelona, Spain), diluted in water in a proportion of $5 \%$ [26]. 

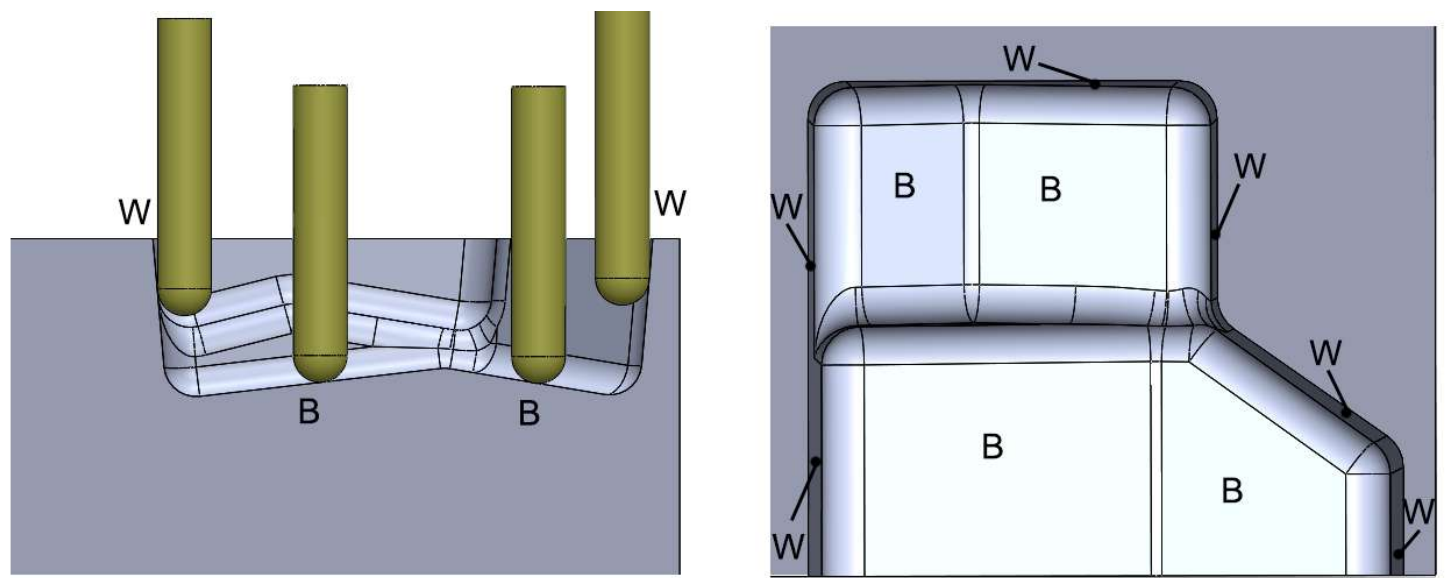

Figure 1. Diagram of the mold used in the tests: section where the gradient of the bottom (B) and the wall (W) are evident (left), and top view of the cavity (right).

The material used to machine the molds was an EN AW 7075 T6. It is an Al-Zn-Mg-(Cu) alloy, hardened by precipitation and with a high resistance to tensile strength $(500-530 \mathrm{MPa})$. It is used to manufacture molds used in the plastic industry [27].

Each cavity was machined in two stages (Figure 2). The roughness stage was carried out with a tungsten-carbide cylindrical flat-end milling tool with an $8 \mathrm{~mm}$ diameter, and two cutting edges with a helical angle of $45^{\circ}$ (DIN 6527). The finishing stage was carried out with a tungsten-carbide hemispherical tool, titanium nitride coated (TiN), with a $5 \mathrm{~mm}$ diameter. The path and working numerical control (NC) code was generated by means of a Mastercam software program (Version v10.2 MR2, CNC Software Inc., Tolland, CT, USA) [28].

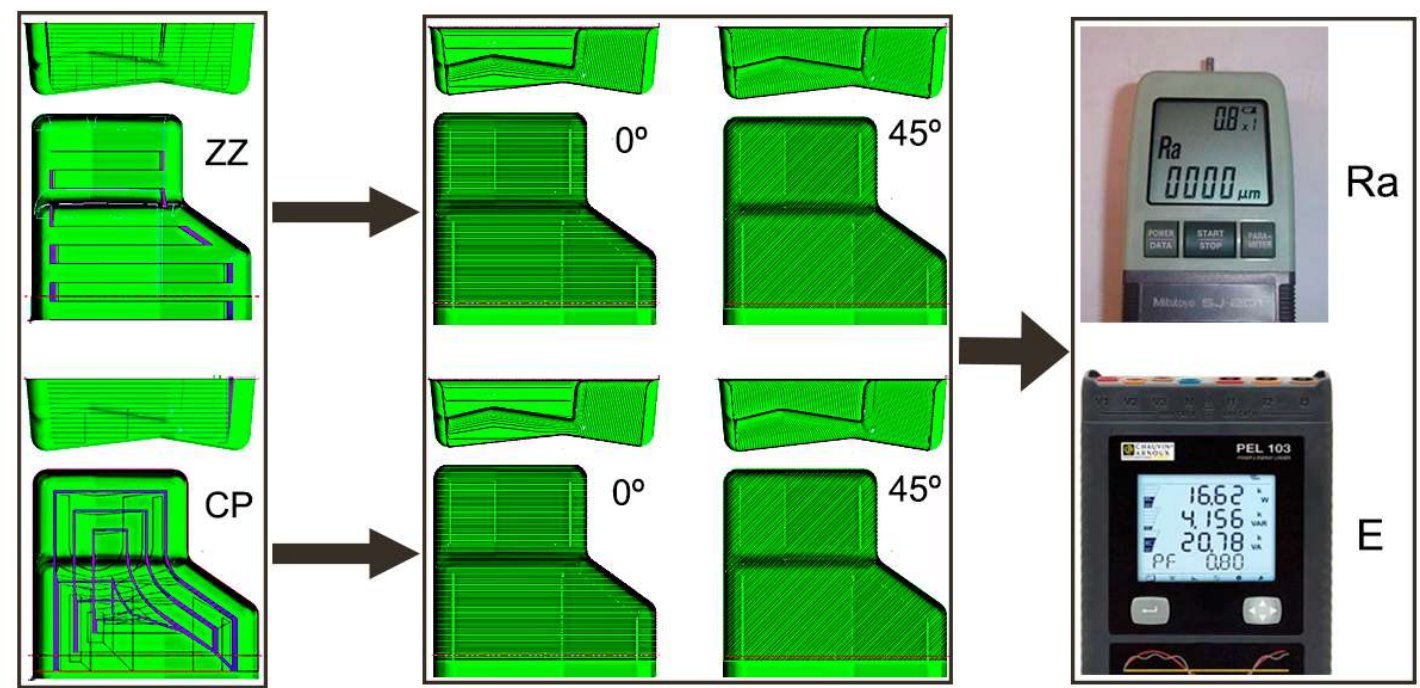

Figure 2. Scheme of the experiments: the strategies used in the roughing stage are zig-zag (ZZ) and contour-parallel (CP) (left), the strategies used in finishing stage are $\mathrm{ZZ} 0^{\circ}$ and $\mathrm{ZZ} 45^{\circ}$ (centre), and Mitutoyo roughness meter and energy data logger employed in the measurements (right).

During the roughing stage, the tool worked according to the manufacturer recommendations: spindle-speed equal to $6366 \mathrm{rpm}$, feed-rate in radial direction equal to $764 \mathrm{~mm} / \mathrm{min}$, feed-rate in axial direction equal to $382 \mathrm{~mm} / \mathrm{min}$, and step-over equal to $4 \mathrm{~mm}$. The values used for the rest of the parameters for roughing and finishing are shown in Table 1. To study the influence of these parameters on the output variables, an orthogonal design of experiments was developed, as seen in Table 2 [29]. 
Table 1. Process parameters and levels.

\begin{tabular}{ccccccc}
\hline & Roughing & \multicolumn{5}{c}{ Finishing } \\
\hline Level & Strategy (A) & $\begin{array}{c}\text { Axial Depth } \\
\text { of Cut, } \mathbf{~ m m} \\
\text { (B) }\end{array}$ & Strategy (C) & $\begin{array}{c}\text { Spindle } \\
\text { Speed, rpm } \\
\text { (D) }\end{array}$ & $\begin{array}{c}\text { Feed Rate, } \\
\text { mm/min (E) }\end{array}$ & $\begin{array}{c}\text { Step-over, } \\
\text { mm (F) }\end{array}$ \\
\hline-1 & Zig-Zag & 1 & Zig-Zag $\left(0^{\circ}\right)$ & 6366 & 764 & 0.1 \\
+1 & Contour-Parallel & 3 & Zig-Zag $\left(45^{\circ}\right)$ & 8000 & 1146 & 0.3 \\
\hline
\end{tabular}

Table 2. Taguchi orthogonal array.

\begin{tabular}{ccccccc}
\hline \multicolumn{3}{c}{ Roughing } & & \multicolumn{4}{c}{ Finishing } \\
\hline No. & $\mathbf{( A )}$ & $\mathbf{( B )}$ & $\mathbf{( C )}$ & $\mathbf{( D )}$ & $\mathbf{( E )}$ & $\mathbf{( F )}$ \\
\hline 1 & -1 & -1 & -1 & -1 & -1 & -1 \\
2 & -1 & -1 & -1 & +1 & -1 & +1 \\
3 & -1 & -1 & -1 & -1 & +1 & +1 \\
4 & -1 & -1 & -1 & +1 & +1 & -1 \\
5 & -1 & -1 & +1 & -1 & -1 & +1 \\
6 & -1 & -1 & +1 & +1 & -1 & -1 \\
7 & -1 & -1 & +1 & -1 & +1 & -1 \\
8 & -1 & -1 & +1 & +1 & +1 & +1 \\
9 & -1 & +1 & -1 & -1 & -1 & +1 \\
10 & -1 & +1 & -1 & +1 & -1 & -1 \\
11 & -1 & +1 & -1 & -1 & +1 & -1 \\
12 & -1 & +1 & -1 & +1 & +1 & +1 \\
13 & -1 & +1 & +1 & -1 & -1 & -1 \\
14 & -1 & +1 & +1 & +1 & -1 & +1 \\
15 & -1 & +1 & +1 & -1 & +1 & +1 \\
16 & -1 & +1 & +1 & +1 & +1 & -1 \\
17 & +1 & -1 & -1 & -1 & -1 & +1 \\
18 & +1 & -1 & -1 & +1 & -1 & -1 \\
19 & +1 & -1 & -1 & -1 & +1 & -1 \\
20 & +1 & -1 & -1 & +1 & +1 & +1 \\
21 & +1 & -1 & +1 & -1 & -1 & -1 \\
22 & +1 & -1 & +1 & +1 & -1 & +1 \\
23 & +1 & -1 & +1 & -1 & +1 & +1 \\
24 & +1 & -1 & +1 & +1 & +1 & -1 \\
25 & +1 & +1 & -1 & -1 & -1 & -1 \\
26 & +1 & +1 & -1 & +1 & -1 & +1 \\
27 & +1 & +1 & -1 & -1 & +1 & +1 \\
28 & +1 & +1 & -1 & +1 & +1 & -1 \\
29 & +1 & +1 & +1 & -1 & -1 & +1 \\
30 & +1 & +1 & +1 & +1 & -1 & -1 \\
31 & +1 & +1 & +1 & -1 & +1 & -1 \\
32 & +1 & +1 & +1 & +1 & +1 & +1 \\
\hline & & & & & & \\
& +1 &
\end{tabular}

The EEC of the machining center was measured on each test by Chauvin Arnoux PEL 103 equipment (Chauvin Arnoux, Paris, France) [20]. The EEC during a milling process depended on the electrical power of the machining center and the machining time:

- According Yoon et al. [19], the energy consumed by a machining center has the following distribution: basic consumption (52\%), coolant pump (19\%), stage movement (1\%), spindle rotation $(21 \%)$, cutting $(7 \%)$. During the tests, the terms basic consumption, coolant pump, and stage movement did not change, so the data logger measures allowed us to know the differences in the terms spindle rotation and cutting.

- In the other hand, every strategy $\left(\mathrm{ZZ}, \mathrm{CP}, \mathrm{ZZ} 0^{\circ}\right.$, and $\left.\mathrm{ZZ} 45^{\circ}\right)$ generated a particular machining time. This fact produced different EEC for the same feed-rate of spindle speed.

The surface roughness was measured by a Mitutoyo roughness meter, SJ-201P model (Mitutoyo Corporation, Sakado, Japan) (Figure 2). Five measurements were taken in each plane of the bottom of the 3-D pocket. The cut-off value was selected as recommended by ISO 4288 [30]. 
To analyze the influence of each parameter or strategy, the Taguchi method was used [31]. This method allows one to find optimal process values for improving the quality characteristics in a manufacturing process [9]. Through the use of orthogonal arrays, the Taguchi method allows one to completely study the space within a parameter with a reduced amount of experiments. Taguchi recommends using the signal-to-noise ratio ( $\mathrm{S} / \mathrm{N}$ ratio) in order to determine the quality characteristics implemented in problems that arise in design engineering (in this instance, "the smaller the better" was used).

In addition to the $\mathrm{S} / \mathrm{N}$ ratio, a statistical analysis of variance (ANOVA) was used to certify the influence of studied parameters and strategies on surface roughness and EEC. In this way, the optimal levels of process parameters and strategies could be estimated.

\section{Results}

The measurements for surface roughness, $R a(\mu \mathrm{m})$, at the base $(\mathrm{B})$ and walls $(\mathrm{W})$ of the molds and the EEC $(\mathrm{kJ})[21,24]$ corresponding to each of the 32 tests undertaken are shown in Table 3. This table also shows the active electrical energy consumed by the machining center during each cycle of milling. From this data, and by means of statistical software, the mean of the means and the signal to noise relation (S/N ratio) was calculated for each parameter and level (Tables 4-9). The results of ANOVA are presented in Tables 10-12.

Table 3. Parameters and strategies studied in the work using an orthogonal design of experiments.

\begin{tabular}{cccccccc}
\hline $\begin{array}{c}\text { Exp. } \\
\text { No. }\end{array}$ & $\begin{array}{c}\text { Bottom Ra } \\
(\boldsymbol{\mu m})\end{array}$ & $\begin{array}{c}\text { Wall Ra } \\
(\boldsymbol{\mu \mathbf { m } )}\end{array}$ & $\begin{array}{c}\text { Electrical Energy } \\
\text { Consumpt. } \\
(\mathbf{k J})\end{array}$ & $\begin{array}{c}\text { Exp. } \\
\mathbf{N o} .\end{array}$ & $\begin{array}{c}\text { Bottom Ra } \\
(\boldsymbol{\mu m})\end{array}$ & $\begin{array}{c}\text { Wall Ra } \\
(\boldsymbol{\mu m})\end{array}$ & $\begin{array}{c}\text { Electrical Energy } \\
\text { Consumpt. } \\
(\mathbf{k J})\end{array}$ \\
\hline 1 & 0.375 & 0.340 & 1892.295 & 17 & 1.096 & 1.180 & 726.544 \\
2 & 1.096 & 0.906 & 952.221 & 18 & 0.378 & 0.302 & 1959.509 \\
3 & 1.115 & 1.112 & 746.164 & 19 & 0.321 & 0.280 & 1246.159 \\
4 & 0.367 & 0.342 & 1745.124 & 20 & 1.067 & 1.130 & 665.313 \\
5 & 0.893 & 1.916 & 852.554 & 21 & 0.411 & 0.410 & 1730.213 \\
6 & 0.349 & 0.496 & 2108.123 & 22 & 1.071 & 1.792 & 857.676 \\
7 & 0.378 & 0.386 & 1407.184 & 23 & 1.127 & 1.836 & 599.942 \\
8 & 0.925 & 1.734 & 736.073 & 24 & 0.453 & 0.420 & 1500.760 \\
9 & 1.160 & 0.918 & 914.459 & 25 & 0.391 & 0.464 & 1466.522 \\
10 & 0.356 & 0.378 & 1850.367 & 26 & 1.097 & 1.010 & 651.152 \\
11 & 0.387 & 0.588 & 1143.106 & 27 & 1.159 & 1.528 & 443.197 \\
12 & 1.167 & 1.934 & 558.109 & 28 & 0.426 & 0.568 & 1317.950 \\
13 & 0.387 & 0.392 & 1877.920 & 29 & 1.109 & 2.012 & 698.821 \\
14 & 0.996 & 2.010 & 846.666 & 30 & 0.356 & 0.492 & 2051.546 \\
15 & 0.984 & 2.020 & 590.787 & 31 & 0.381 & 0.402 & 1296.372 \\
\hline
\end{tabular}

Table 4. $R a$ response table for surface roughness at the bottom $(\mu \mathrm{m})$.

\begin{tabular}{ccccccc}
\hline Levels & A & B (mm) & C & D (rpm) & E (mm/min) & F (mm) \\
\hline-1 & 0.7505 & 0.7139 & 0.7475 & 0.7297 & 0.7201 & 0.3801 \\
+1 & 0.7063 & 0.7429 & 0.7093 & 0.7270 & 0.7366 & 1.0767 \\
$\Delta_{\text {max }}$ min & 0.0442 & 0.0290 & 0.0383 & 0.0027 & 0.0165 & 0.6966 \\
Classification & 2 & 4 & 3 & 6 & 5 & 1 \\
\hline
\end{tabular}

Table 5. S/N response table for surface roughness at the bottom.

\begin{tabular}{ccccccc}
\hline Levels & A & B (mm) & C & D (rpm) & E (mm/min) & F (mm) \\
\hline 1 & 3.6584 & 4.0406 & 3.7795 & 3.9017 & 3.9996 & 8.4293 \\
2 & 4.1559 & 3.7736 & 4.0348 & 3.9125 & 3.8147 & -0.6150 \\
$\Delta_{\text {max-min }}$ & 0.4974 & 0.2670 & 0.2553 & 0.0108 & 0.1849 & 9.0443 \\
Classification & 2 & 3 & 4 & 6 & 5 & 1 \\
\hline
\end{tabular}


Table 6. $R a$ response table for surface roughness at the wall $(\mu \mathrm{m})$.

\begin{tabular}{ccccccc}
\hline Levels & A & B (mm) & C & D (rpm) & E (mm/min) & F (mm) \\
\hline-1 & 0.9901 & 0.9114 & 0.8113 & 0.9865 & 0.9386 & 0.4299 \\
+1 & 1.0056 & 1.0844 & 1.1845 & 1.0092 & 1.0571 & 1.5659 \\
$\Delta_{\text {max }- \text { min }}$ & 0.0155 & 0.1730 & 0.3733 & 0.0227 & 0.1185 & 1.1360 \\
Classification & 6 & 3 & 2 & 5 & 4 & 1 \\
\hline
\end{tabular}

Table 7. S/N response table for surface roughness at the wall.

\begin{tabular}{ccccccc}
\hline Levels & A & B (mm) & C & D (rpm) & E (mm/min) & F (mm) \\
\hline 1 & 2.1013 & 2.9030 & 3.3421 & 2.2105 & 2.5153 & 7.5513 \\
2 & 1.9234 & 1.1217 & 0.6826 & 1.8142 & 1.5094 & -3.5266 \\
$\Delta_{\text {max }}$ min & 0.1778 & 1.7812 & 2.6594 & 0.3963 & 1.0059 & 11.0779 \\
Classification & 6 & 3 & 2 & 5 & 4 & 1 \\
\hline
\end{tabular}

Table 8. Response table for EEC (kJ).

\begin{tabular}{ccccccc}
\hline Levels & A & B (mm) & C & D (rpm) & E (mm/min) & F (mm) \\
\hline-1 & 1114.4 & 1232.9 & 1142.4 & 1102.0 & 1339.8 & 1648.8 \\
+1 & 1250.5 & 1132.1 & 1222.6 & 1262.9 & 1025.2 & 716.1 \\
$\Delta_{\text {max }- \text { min }}$ & 136.1 & 100.8 & 80.2 & 160.9 & 314.6 & 932.6 \\
Classification & 4 & 5 & 6 & 3 & 2 & 1 \\
\hline
\end{tabular}

Table 9. S/N response table for EEC.

\begin{tabular}{ccccccc}
\hline Levels & A & B (mm) & C & D (rpm) & E (mm/min) & F (mm) \\
\hline 1 & -60.01 & -61.05 & -60.28 & -60.05 & -61.75 & -64.19 \\
2 & -61.12 & -60.08 & -60.85 & -61.08 & -59.38 & -56.94 \\
$\Delta_{\text {max }- \text { min }}$ & 1.12 & 0.97 & 0.57 & 1.04 & 2.37 & 7.26 \\
Classification & 3 & 5 & 6 & 4 & 2 & 1 \\
\hline
\end{tabular}

Table 10. ANOVA results for surface roughness at the bottom of the mold.

\begin{tabular}{ccccc}
\hline Source of Variation & Degree of Freedom & Sum of Squares & F Ratio & $p$ Value \\
\hline A & 1 & 0.01561 & 4.54 & 0.043 \\
B & 1 & 0.00673 & 1.96 & 0.174 \\
C & 1 & 0.01170 & 3.41 & 0.077 \\
D & 1 & 0.00006 & 0.02 & 0.899 \\
E & 1 & 0.00218 & 0.63 & 0.434 \\
F & 1 & 3.88183 & 1129.33 & 0.000 \\
\hline Error & 25 & 0.08593 & - & - \\
\hline Total & 31 & 4.00403 & - & - \\
\hline
\end{tabular}

Table 11. ANOVA results for surface roughness at walls.

\begin{tabular}{ccccc}
\hline Source of Variation & Degree of Freedom & Sum of Squares & F Ratio & $p$ Value \\
\hline A & 1 & 0.0019 & 0.03 & 0.864 \\
B & 1 & 0.2394 & 3.73 & 0.065 \\
C & 1 & 1.1145 & 17.37 & 0.000 \\
D & 1 & 0.0041 & 0.06 & 0.802 \\
E & 1 & 0.1123 & 1.75 & 0.198 \\
F & 1 & 10.3240 & 160.86 & 0.000 \\
\hline Error & 25 & 1.6045 & - & - \\
\hline Total & 31 & 13.4009 & - & - \\
\hline
\end{tabular}


Table 12. ANOVA results for EEC.

\begin{tabular}{ccccc}
\hline Source of Variation & Degree of Freedom & Sum of Squares & F Ratio & $p$ Value \\
\hline A & 1 & 148,292 & 8.43 & 0.008 \\
B & 1 & 81,264 & 4.62 & 0.041 \\
C & 1 & 51,419 & 2.92 & 0.100 \\
D & 1 & 207,149 & 11.78 & 0.002 \\
E & 1 & 791,929 & 45.02 & 0.000 \\
F & 1 & $6,958,669$ & 395.62 & 0.000 \\
\hline Error & 25 & 439,727 & - & - \\
\hline Total & 31 & - & - & - \\
\hline
\end{tabular}

The $R_{a}$ response results at the bottom are given in Table 4 . As can be seen, the parameter step-over in finishing $(\mathrm{F})$ were the most influential on those analyzed. Following this, in order of importance, was the strategy on roughness (A). Both parameters, (F) and (A), were those that had the most effect on the $\mathrm{S} / \mathrm{N}$ ratio (Table 5) and presented a $p$-value under 0.05 (Table 10).

The $R_{a}$ response results at the wall are given in Table 6 . In this case, the parameter for the step-over (F) was also the parameter with the greatest influence. Following this, in order of importance, was the strategy on finishing (C). Both parameters, $(\mathrm{F})$ and $(\mathrm{C})$ were those with the greatest effect on the $\mathrm{S} / \mathrm{N}$ ratio (Table 7) and presented a $p$-value under 0.05 (Table 11).

The response results for EEC are presented in Table 8. The step-over $(F)$ was again the most influential parameter. It was followed by, in order of importance, the feed-rate programmed in the finishing operation (E). Both parameters, (F) and (E) were those that had the greatest effect on the $\mathrm{S} / \mathrm{N}$ ratio (Table 9). In this occasion, the parameters (F), (E), (D), (A), and (B) presented a $p$-value under 0.05 (Table 12). However, (F) and (E) had the highest importance, as they had the highest F-ratio.

In Figure 3, the roughness of the base of the cavity obtained, in each of the tests, was related to the electrical energy invested in machining the aforementioned 3-D pocket (each point on the graph represents one test). Figure 4 shows the existing relation between the surface roughness obtained on the walls on each cavity with the active power used in its machining.

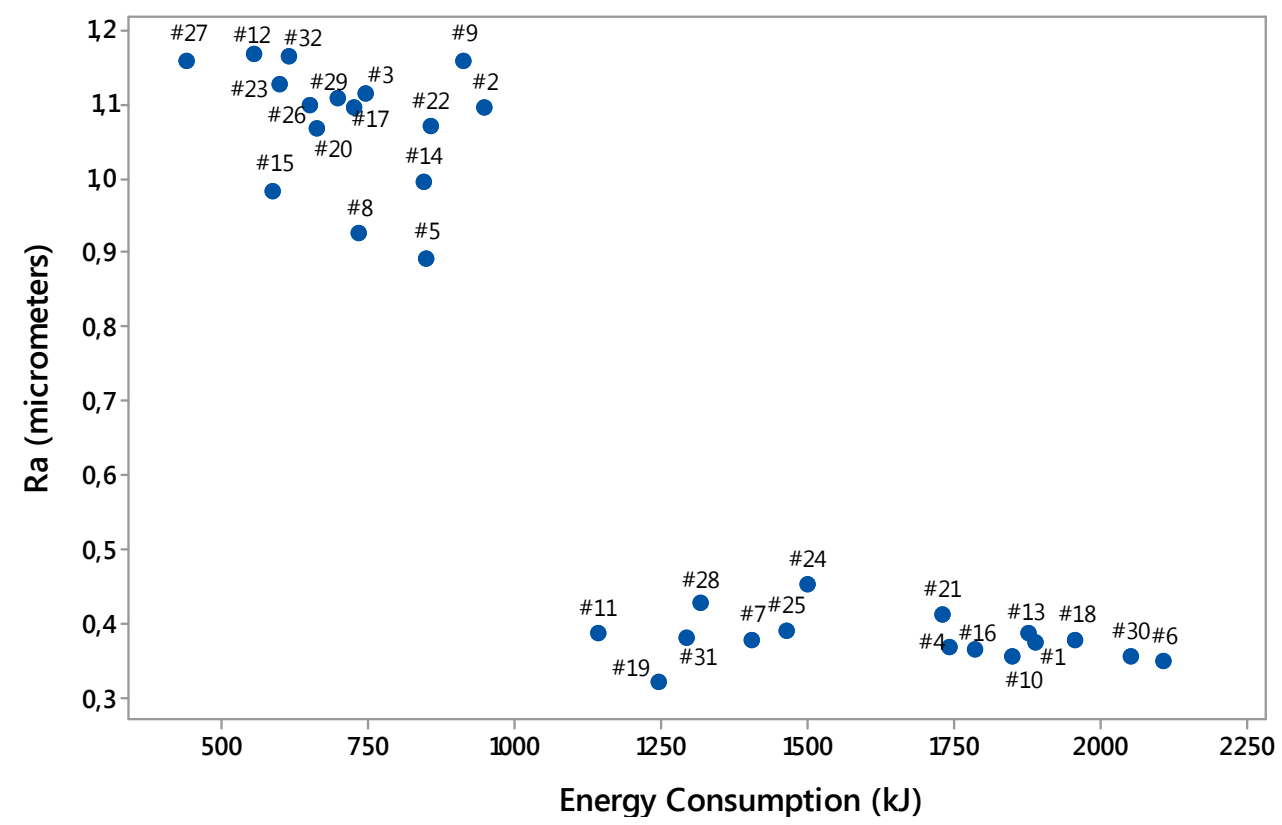

Figure 3. Electrical energy used in milling in each mold against the surface roughness obtained at the bottom of each one (each point corresponds to one of the tests undertaken in this study). 


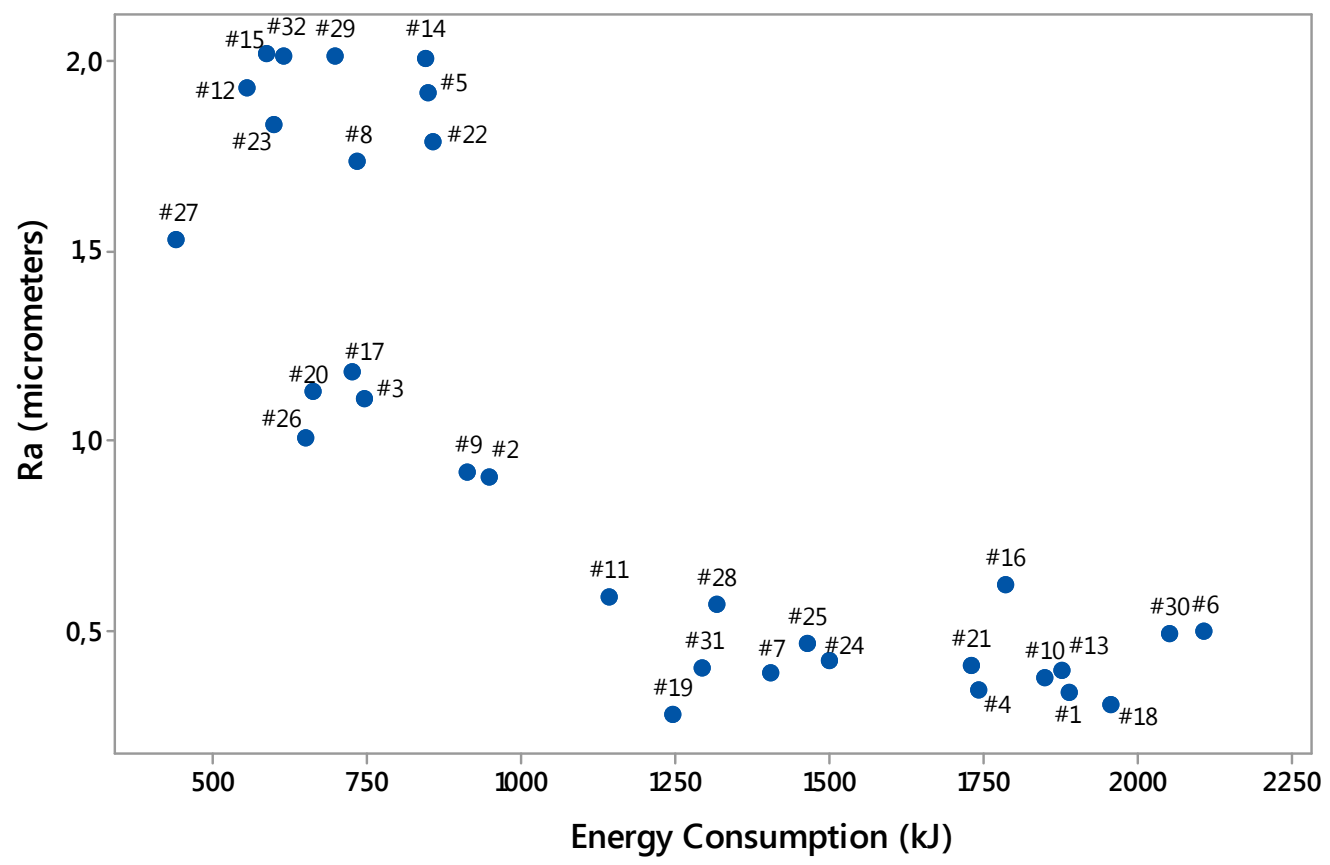

Figure 4. Electrical energy used in milling in each mold against the surface roughness obtained on the walls of each one (each point corresponds to one of the tests undertaken in this study).

\section{Discussion}

The present work has studied the influence of cutting parameters and cutting strategies, as much in roughing as in finishing, relative to surface roughness and EEC used during the machining of molds. To this end, 32 molds were machined, following an orthogonal design of experiments. In addition, the combinations that showed the best results from the point of view of the EEC during the mold manufacturing cycle have been determined.

In the literature, this problem has been studied beforehand [9]. Nevertheless, no works have been found that take into account the parameters and strategies on the roughing phase [13] and approach of the reduction of EEC.

The results of the tests allow one to come to the following conclusions:

- The step-over in the finishing (F) was the most influential in the surface roughness of the bottom (Tables 4 and 5) and of the walls of the 3-D pockets (Tables 6 and 7). This was confirmed in the analysis ANOVA (Tables 9 and 10). Lower values of this parameter produced a better surface roughness; however, this choice meant a higher EEC (Tables 8 and 12). These results coincided with those obtained by Baptista and Antune [32].

- The strategy used in the roughing (A) had some influence on the surface roughness on the bottom of the 3-D pocket (Table 10). The use of ZZ gave a better surface quality (Tables 4 and 5), although it resulted in greater EEC (Table 8). No previous works have been found that have studied the influence of the roughing strategy on the final surface roughness. This finding can be considered the main contribution of the work.

- The strategy used in finishing $(C)$ was an influential factor on the surface roughness on the walls (Table 11). The $\mathrm{ZZ}\left(0^{\circ}\right)$ produces a better surface roughness than the $\mathrm{ZZ}\left(45^{\circ}\right)$ (Tables 6 and 7 ); this was due to the contact tool-surface [14]. In the present study, strategy in finishing (C) had no relation to the EEC (Tables 8 and 12). However, diverse authors have compared other finishing strategies, concluding that a 3-D offset is the most efficient $[13,14]$.

- Certain parameters that do not seem to have much relevance on the surface roughness do however have an influence on the effective EEC during the manufacturing of the molds (Table 12). This is 
the case with: axial depth of path in the roughing (B), spindle-speed used in finishing (D), and feed-rate in finishing (E). Oda et al. [33] also concluded that large feed rate values led to reduced power consumption.

- Figure 3 shows a diagram of dispersion with the 32 tests undertaken, where the $x$-axis corresponds to EEC and the $y$-axis corresponds to the surface roughness on the bottom of the 3-D pocket. Here there are two clusters of very polarized points. The first group is made up of the greater values of surface roughness ( $R a>0.9$ micrometers) but which have required low EEC $(\mathrm{EEC}<1000 \mathrm{~kJ})$. The second group is made up of tests with low values of surface roughness $(R a<0.5$ micrometers) but are associated with high EEC values (EEC $>1000 \mathrm{~kJ})$. In Figure 4, relative to surface roughness on the walls, one can appreciate an additional group, between the aforementioned groups.

- $\quad$ Test 19 produced a better finish as much on the bottom as on the walls of the mold, requiring lower EEC. This test was undertaken with a roughness strategy $\mathrm{CP}$, an axial depth of cut for roughness of $1 \mathrm{~mm}$, a finishing strategy $\mathrm{ZZ}\left(0^{\circ}\right)$, a spindle-speed of $6366 \mathrm{rpm}$, a feed-rate on the finishing of $1146 \mathrm{~mm} / \mathrm{min}$, and a step-over in the finishing of $0.1 \mathrm{~mm}$.

- An adequate selection of parameters and strategies allowed for an improvement of $70 \%$ in the surface roughness of the mold, with an electrical energy saving of $40 \%$.

The ZZ roughing strategy produced a remaining material whose morphology presented a clear directionality characteristic (Figure 5). On the other hand, the CP strategy used for roughing produced a remaining material whose morphology presented steps whose height was equivalent to the depth of passage and multiple changes of direction were seen in the way in which these remains were presented in the form of steps. This difference in the morphology of the remaining material has been indirectly affected in the finishing results.
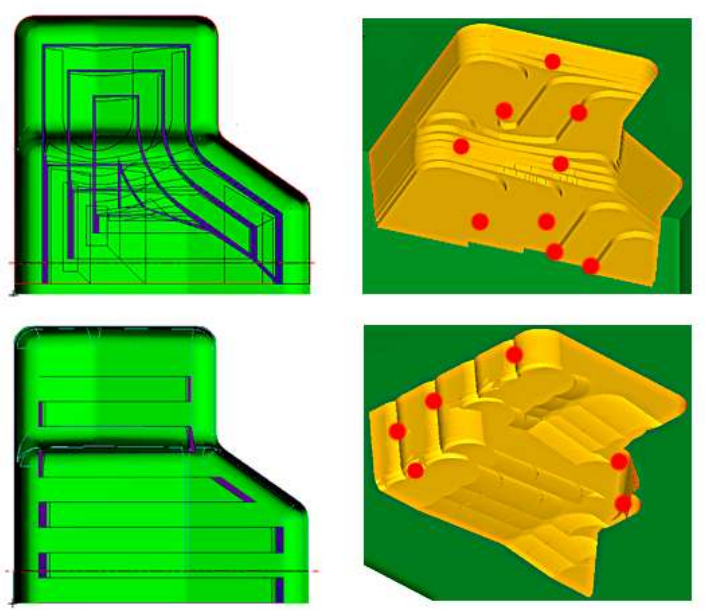

Figure 5. Scheme of the morphology and points of discontinuity presented in the remaining material after roughing strategies, with contour parallel (up) and zig-zag (down).

The load on the finishing endmill tool suffered many changes of direction and discontinuities when the remaining material presented the morphology obtained in the roughing by the $\mathrm{CP}$ strategy, while the directionality of the cutting load was more stable when it presented the morphology obtained in the case of the roughing ZZ.

This phenomenon caused by the changes of direction and discontinuities in the loading of the finishing tool may have caused more vibrations in the finishing tool and in the piece itself during the finishing operation. It has been possible to verify that when the load of the finishing tool was affected to a lesser extent by the changes of direction in the material to be eliminated, the obtained superficial quality was better. 


\section{Conclusions}

In the present work, cutting strategies and cutting parameters in roughing and finishing stages have been studied in order to reach better surface roughness values with a lower EEC during the manufacturing of EN-AW 7075 T6 molds via a machining process.

The results obtained allow us to affirm that lower values in step-over in the finishing stage were absolutely necessary in order to obtain a good surface roughness (both in the bottom and on the walls of the mold), although this resulted in higher EEC.

The strategies for roughing and finishing had an influence on the surface roughness on the bottom and the walls, respectively. The strategy chosen for roughing also had an influence on the EEC of the machining center.

It has also been demonstrated that an adequate choice of values for certain variables (axial depth of cut in roughing, feed-rate in finishing, and spindle-speed in finishing) allowed for the manufacturing of molds with a lower EEC without negative repercussions on the resulting surface roughness. The most satisfactory test showed an improvement in surface quality of $70 \%$, and a reduction in EEC of $40 \%$ (compared to the more unfavorable tests).

Future research will concentrate on searching for new parameters and strategies that allow even further reduction in EEC in the processes of manufacturing molds by machine production. A study will also be carried out on the wear of the tools and the influence of the use of coolant in the surface roughness and EEC.

Author Contributions: Conceptualization, O.R.-A., G.G.-V. and P.E.R.; Methodology, O.R.-A. and P.E.R.; Software, O.R.-A. and P.E.R.; Validation, P.E.R.; Formal Analysis, M.T.B. and P.E.R.; Investigation, O.R.-A., M.T.B. and P.E.R.; Data Curation, M.T.B. and P.E.R.; Writing-Original Draft Preparation, O.R.-A., M.T.B. and P.E.R.; Writing-Review \& Editing, O.R.-A., G.G.-V. and P.E.R.; Supervision, P.E.R.; Project Administration, P.E.R.

Funding: This research received no external funding.

Conflicts of Interest: The authors declare no conflict of interest.

\section{References}

1. Groover, M.P. Fundamentals of Modern Manufacturing; Wiley: Hoboken, NJ, USA, 2015.

2. Krajnik, P.; Kopač, J. Modern machining of die and mold tools. J. Mater. Process. Technol. 2004, 157-158, 543-552. [CrossRef]

3. Romero-Carrillo, P.; Torres-Jimenez, E.; Dorado, R.; Daz-Garrido, F. Analytic construction and analysis of spiral pocketing via linear morphing. CAD Comput. Aided Des. 2015, 69, 1-10. [CrossRef]

4. Wang, M.Y.; Chang, H.Y. Experimental study of surface roughness in slot end milling AL2014-T6. Int. J. Mach. Tools Manuf. 2004, 44, 51-57. [CrossRef]

5. Öktem, H.; Erzurumlu, T.; Kurtaran, H. Application of response surface methodology in the optimization of cutting conditions for surface roughness. J. Mater. Process. Technol. 2005, 170, 11-16. [CrossRef]

6. Petek, A.; Kuzman, K.; Kopac, J. Deformations and forces analysis of single point incremental sheet metal forming. Arch. Mater. Sci. Eng. 2009, 35, 107-116.

7. Kopac, J.; Krajnik, P. Robust design of flank milling parameters based on grey-Taguchi method. J. Mater. Process. Technol. 2007, 191, 400-403. [CrossRef]

8. Jiang, F.; Li, J.; Yan, L.; Sun, J.; Zhang, S. Optimizing end-milling parameters for surface roughness under different cooling/lubrication conditions. Int. J. Adv. Manuf. Technol. 2010, 51, 841-851. [CrossRef]

9. Öktem, H.; Erzurumlu, T.; Çöl, M. A study of the Taguchi optimization method for surface roughness in finish milling of mold surfaces. Int. J. Adv. Manuf. Technol. 2006, 28, 694-700. [CrossRef]

10. Yao, C.; Tan, L.; Yang, P.; Zhang, D. Effects of tool orientation and surface curvature on surface integrity in ball end milling of TC17. Int. J. Adv. Manuf. Technol. 2018, 94, 1699-1710. [CrossRef]

11. Gologlu, C.; Sakarya, N. The effects of cutter path strategies on surface roughness of pocket milling of 1.2738 steel based on Taguchi method. J. Mater. Process. Technol. 2008, 206, 7-15. [CrossRef]

12. Romero, P.E.; Dorado, R.; Díaz, F.A.; Rubio, E.M. Influence of pocket geometry and tool path strategy in pocket milling of UNS A96063 alloy. Procedia Eng. 2013, 63, 523-531. [CrossRef] 
13. Ramos, A.M.; Relvas, C.; Simões, J.A. The influence of finishing milling strategies on texture, roughness and dimensional deviations on the machining of complex surfaces. J. Mater. Process. Technol. 2003, 136, 209-216. [CrossRef]

14. De Souza, A.F.; Machado, A.; Beckert, S.F.; Diniz, A.E. Evaluating the roughness according to the tool path strategy when milling free form surfaces for mold application. Procedia CIRP 2014, 14, 188-193. [CrossRef]

15. Schützer, K.; Helleno, A.L.; Pereira, S.C. The influence of the manufacturing strategy on the production of molds and dies. J. Mater. Process. Technol. 2006, 179, 172-177. [CrossRef]

16. Krimpenis, A.; Fousekis, A.; Vosniakos, G. Assessment of sculptured surface milling strategies using design of experiments. Int. J. Adv. Manuf. Technol. 2005, 25, 444-453. [CrossRef]

17. O'Driscoll, E.; Kelly, K.; O'Donnell, G.E. Intelligent energy based status identification as a platform for improvement of machine tool efficiency and effectiveness. J. Clean. Prod. 2015, 105, 184-195. [CrossRef]

18. Kong, D.; Choi, S.; Yasui, Y.; Pavanaskar, S.; Dornfeld, D.; Wright, P. Software-based tool path evaluation for environmental sustainability. J. Manuf. Syst. 2011, 30, 241-247. [CrossRef]

19. Yoon, H.S.; Lee, J.Y.; Kim, H.S.; Kim, M.S.; Kim, E.S.; Shin, Y.J.; Chu, W.S.; Ahn, S.H. A comparison of energy consumption in bulk forming, subtractive, and additive processes: Review and case study. Int. J. Precis. Eng. Manuf. Green Technol. 2014, 1, 261-279. [CrossRef]

20. Priarone, P.C. Quality-conscious optimization of energy consumption in a grinding process applying sustainability indicators. Int. J. Adv. Manuf. Technol. 2016, 86, 2107-2117. [CrossRef]

21. Edem, I.F.; Mativenga, P.T. Modelling of energy demand from computer numerical control (CNC) toolpaths. J. Clean. Prod. 2017, 157, 310-321. [CrossRef]

22. Guerra-Zubiaga, D.A.; Al Mamun, A.; Gonzalez-Badillo, G. An energy consumption approach in a manufacturing process using design of experiments. Int. J. Comput. Integr. Manuf. 2018, 1-11. [CrossRef]

23. Kant, G.; Sangwan, K.S. Prediction and optimization of machining parameters for minimizing power consumption and surface roughness in machining. J. Clean. Prod. 2014, 83, 151-164. [CrossRef]

24. Xu, K.; Tang, K. An energy saving approach for rough milling tool path planning. Comput. Aided Des. Appl. 2016, 13, 253-264. [CrossRef]

25. Pavanaskar, S.; Pande, S.; Kwon, Y.; Hu, Z.; Sheffer, A.; McMains, S. Energy-efficient vector field based toolpaths for CNC pocketmachining. J. Manuf. Process. 2015, 20, 314-320. [CrossRef]

26. Brugarolas Besal 5. Available online: http://portal.suministrosherco.com/herco/doc/HERCO_ _DOC0004813_HT-BESAL_5_(08.02.13).pdf (accessed on 17 August 2018).

27. Oktem, H.; Erzurumlu, T.; Uzman, I. Application of Taguchi optimization technique in determining plastic injection molding process parameters for a thin-shell part. Mater. Des. 2007, 28, 1271-1278. [CrossRef]

28. Mastercam, Version 10.2 MR2; CNC Software Inc.: Tolland, CT, USA, 2005.

29. Montgomery, D. Design and Analysis of Experiments; John Wiley \& Sons Inc.: Hoboken, NJ, USA, 2012; ISBN 978-1-118-14692-7.

30. Geometrical Product Specifications (GPS). Surface Texture: Profile Method. Rules and Procedures for the Assessment of Surface Texture (ISO 4288:1996); International Standard Organization: Geneva, Switzerland, 1998.

31. Roy, R. A Primer on Taguchi Method; Society of Manufacturing Engineers (SME): Dearborn, Michigan, 2010; ISBN 978-0872638648.

32. Baptista, R.; Antune Simões, J.F. Three and five axes milling of sculptured surfaces. J. Mater. Process. Technol. 2000, 103, 398-403. [CrossRef]

33. Oda, Y.; Mori, M.; Ogawa, K.; Nishida, S.; Fujishima, M.; Kawamura, T. Study of optimal cutting condition for energy efficiency improvement in ball end milling with tool-workpiece inclination. CIRP Ann. Manuf. Technol. 2012, 61, 119-122. [CrossRef]

(C) 2018 by the authors. Licensee MDPI, Basel, Switzerland. This article is an open access article distributed under the terms and conditions of the Creative Commons Attribution (CC BY) license (http:/ / creativecommons.org/licenses/by/4.0/). 